\title{
Spontaneous alternation in ferrets following treatment with scopolamine, chlordiazepoxide, and caffeine
}

\author{
R. N. HUGHES and ANDREA M. GREIG \\ University of Canterbury, Christchurch, 1, New Zealand
}

\begin{abstract}
Spontaneous alternation frequencies were observed in ferrets following injections of saline or two doses of scopolamine, chlordiazepoxide, or caffeine. All three drugs significantly reduced alternation while having no effect on choice latencies. The results were discussed in the light of their comparative relevance and theories based on central cholinergic activity.
\end{abstract}

The anticholinergic drug, scopolamine, has often been shown to reduce spontaneous alternation in rats (e.g., Douglas \& Isaacson, 1966; Meyers \& Domino, 1964; Squire, 1969). Alternation is generally accepted as a response to the more novel of two $\mathrm{T}$ or $\mathrm{Y}$-maze arms (Dember, 1961). Carlton (1969) interprets scopolamine's effects on the behavior as attenuation of habituation to the novelty of the arm chosen on Trial 1 . According to this view, habituation is regulated by central cholinergic activity (possibly in the hippocampus, Carlton, 1966), so that scopolamine's effect is explained by blocking of acetylcholine action. Likewise, increased alternation following treatment with the anticholinesterase, physostigmine (Baisden, Isaacson, Woodruff; Squire, 1969; Van Hartesveldt, 1972) could be accounted for by facilitated habituation as a result of higher brain acetylcholine levels (Carlton, 1969).

There are, however, other drugs not commonly regarded as cholinergically active which also reduce alternation, namely d-amphetamine (Atkins, Packwood, \& Marshall, 1969) and chlordiazepoxide (Iwahara, Oishi, Yamazaki, \& Sakai, 1972). Although amphetamine has central adrenergic properties (Stein \& Wise, 1970) it has been shown to reduce amounts of brain acetylcholine (Domino \& Olds, 1972). On the other hand, chlordiazepoxide does not seem to affect central acetylcholine levels (Domino \& Olds, 1972; Sternbach, Randall, \& Gustafson, 1964) but, contrary to amphetamine, it shares with scopolamine a common inhibitory effect on hippocampal theta activity (Iwahara et al., 1972) thus suggesting hippocampal involvement. So, these reports of drug-suppressed alternation may be interpreted as supporting either cholinergic or hippocampal involvement in habituation, but not both! In view of the obvious need for more descriptions of drug effects on alternation and the sparcity of nonrodent research in this area, it was decided to examine the effects of scopolamine and two other unrelated drugs on alternation in ferrets. The ferret is a primitive mustelid carnivore which, because of its size

Requests for reprints should be sent to R. N. Hughes, Department of Psychology, University of Canterbury, Christchurch, 1, New Zealand. and shape, is ideally suited to conventional alternation studies (Eastment \& Hughes, 1968; Hughes, 1965, 1967).

\section{METHOD}

\section{Subjects and Apparatus}

Twenty-nine adult ferrets (Mustela putorius) were used as subjects. The apparatus was a midgray wooden Y-maze $15 \mathrm{~cm}$ wide and $25 \mathrm{~cm}$ high with an angle of 90 deg between the arms. The lengths of each arm, the stem, and the startbox were 66,67 , and $36 \mathrm{~cm}$, respectively. The startbox and arms could be divided off from the stem by guillotine doors.

\section{Procedure}

The ferrets were randomly divided into two groups of 10 subjects each and one of 9 subjects. Each recently fed and watered subject was given seven successive free choices (i.e., six alternation opportunities) on each of 3 days, $30 \mathrm{~min}$ after intraperitoneal injections of saline or two doses of drug $(1 \mathrm{ml} / \mathrm{kg})$. Approximately $48 \mathrm{~h}$ separated each experimental session. One group (ten subjects) was tested following treatment with saline, .15 or $.6 \mathrm{mg} / \mathrm{kg}$ of scopolamine hydrobromide; another (10 subjects) following saline, 5.0 or $7.5 \mathrm{mg} / \mathrm{kg}$ of chlordiazepoxide hydrochloride; and the third ( 9 subjects) following saline, 10.0 or $20.0 \mathrm{mg} / \mathrm{kg}$ of caffeine alkaloid. (Drug doses were based on unpublished findings from this laboratory). At least one subject in each group experienced the saline and two drug doses in each of the six possible three-session sequences.

Testing involved allowing the subject access to the two arms and then lowering the guillotine door behind it when it had entered one of them. After about $10 \mathrm{sec}$, it was removed and the procedure repeated a further six times. The arm chosen and the interval between leaving the startbox and entering it were recorded for each choice.

\section{RESULTS}

For each subject, the total number of alternations and total choice latencies were determined for each level of the drug it experienced. Separate repeated-measures analyses of variance were then performed on the two indices for each group of ferrets. The results are presented in Table 1.

The overall drug effect on alternation was significant for all three compounds. Newman-Keuls tests showed that both doses of each drug significantly reduced alternation (scopolamine and chlordiazepoxide $\mathrm{p}<.01$, 
Table 1

Alternations and Choice Latencies Following Three Levels of Three Drugs and Results of F Tests

\begin{tabular}{|c|c|c|c|c|c|c|}
\hline & Saline & $.15 \mathrm{mg} / \mathrm{kg}$ & $.6 \mathrm{mg} / \mathrm{kg}$ & $\mathrm{F}$ & df & $\mathrm{p}$ \\
\hline & \multicolumn{6}{|c|}{ Scopolamine $(N=10)$} \\
\hline Mean Alternations & 4.7 & 3.4 & 3.3 & 6.93 & $2 / 18$ & $<.01$ \\
\hline \multirow{2}{*}{ Mean Choice Latencies (Per Trial) } & 7.6 & 7.6 & 9.4 & 1.22 & $2 / 18$ & n.s. \\
\hline & \multicolumn{6}{|c|}{ Chlordiazepoxide $(\mathrm{N}=10)$} \\
\hline Mean Alternations & 5.0 & 2.9 & 2.7 & 42.62 & $2 / 18$ & $<.001$ \\
\hline \multirow[t]{2}{*}{ Mean Choice Latencies (Per Trial) } & 7.0 & 6.4 & 5.3 & .09 & $2 / 18$ & n.s. \\
\hline & \multicolumn{6}{|c|}{ Caffeine $(\mathrm{N}=9)$} \\
\hline Mean Alternations & 4.5 & 3.6 & 3.6 & 3.82 & $2 / 16$ & $<.05$ \\
\hline Mean Choice Latencies (Per Trial) & 8.9 & 8.7 & 14.6 & 3.10 & $2 / 16$ & n.s. \\
\hline
\end{tabular}

caffeine $\mathrm{p}<.05$ ) but the difference between these doses was not significant in any case. For all three groups of subjects, choice latencies were not significantly affected by drug treatment.

\section{DISCUSSION}

It is clear that, while all three drugs reduced alternation, these reductions were not related to changes in interchoice intervals (as indicated by choice latencies). The scopolamine and chlordiazepoxide results confirm rat findings (Douglas \& Isaacson, 1966; Iwahara et al., 1972; Meyers \& Domino, 1964; Squire, 1969) and because the latter compound does not influence central acetylcholine levels (Domino \& Olds, 1972; Sternbach et al., 1964), they further question the exclusive control of habituation by cholinergic mechanisms.

The effects of caffeine were entirely contrary to those reported earlier for rats (Cox, 1970). Perhaps Cox's result is specific to laboratory rats or else the present caffeine effect might be a purely ferret phenomenon. It is obvious that more research is required with other species before general statements can be made about drug effects on alternation behaviour and the central control of responses to novelty.

If, as in the present study, several different drugs can have similar behavioral effects, one must question the wisdom of adhering to explanations of behavior based on unitary central processes. It is conceivable that habituation and cholinergic activity are indeed related in the manner suggested by Carlton (1969), although a theory involving cholinergically mediated stimulus sensitivity or attention (such as Warburton's, 1972) might equally well acount for changes in responsiveness to novelty (Warburton, D. M., Personal Communication, April 1973). In view of evidence that rats can "notice" a novel T-maze arm without necessarily entering it (Hughes, 1966), there is also a possibility that spontaneous alternation may depend on other factors [such as preferences for particular degrees of novelty (Montgomery, 1955)] as well as habituation or attention.

\section{REFERENCES}

Atkins, J., Packwood, J. W., \& Marshall, G. L. Spontaneous alternation and D-amphetamine. Psychonomic Science, 1969. 17, 167-168.

Baisden, R. H., Isaacson, R. L., Woodruff, M. L., \& Van Hartesveldt, D. The effect of physostigmine on spontaneous alternation in infant rabbits. Psychonomic Science, 1972, 26, 287-288.

Carlton, P. L. Scopolamine, amphetamine and light-reinforced responding. Psychonomic Science, 1966, 5, 347-348.

Carlton, P. L. Brain-acetylcholine and inhibition. In J. T. Tapp (Ed.), Reinforcement and behavior. New York: Academic Press, 1969. Pp. 286-327.

Cox, T. The effects of caffeine, alcohol, and previous exposure to the test situation on spontaneous alternation Psychopharmacologia (Berlin), 1970, 17, 83-88.

Dember, W. N. Alternation behavior. In D. W. Fiske and S. R. Maddi (Eds.), Functions of varied experience. Homewood, Illinois: Dorsey Press, 1961. Pp. 227-252.

Domino, E. F., \& Olds, N. E. Effects of d-amphetamine scopolamine, chlordiazepoxide and diphenylhydantoin on self-stimulation behaviour and brain acetylcholine. Psy chopharmacologia (Berlin), 1972, 23, 1-16.

Douglas, R. J., \& Isaacson, R. L. Spontaneous alternation and scopolamine. Psy chonomic Science, 1966, 4, 283-284.

Eastment, A. M., \& Hughes, R. N. Reactions of ferret-polecat hybrids to complexity and change. Perceptual and Motor Skills, 1968, 26, 935-938.

Hughes, R. N. Spontaneous alternation and response to stimulus change in the ferret. Journal of Comparative and Physiological Psychology, 1965, 60, 149-150.

Hughes, R. N. Stimulus-change effects of forcing in alternation behavior. Psy chological Reports, 1966, 19, 515-518.

Hughes, R. N. Effects of intertrial confinement and brightness change on ferret alternation behavior. Psychological Reports, $1967,20,679-681$

Iwahara, S., Oishi, H., Yamazaki, S., \& Sakai, K. Effects of chlordiazepoxide upon spontaneous alternation and the hippocampal electrical activity in white rats. Psychopharmacologia (Berlin), 1972, 24, 496-507.

Meyers, B., \& Domino, E. F. The effect of cholinergic blocking drugs on spontaneous alternation in rats. Archives Internationales de Pharmacodynamie et de Thérapie, 1964, 150, 525-529.

Montgomery, K. C. The relation between fear induced by novel stimulation and exploratory behavior. Journal of Comparative and Physiological Psy chology, 1955, 48, 225-228.

Squire, L. R. Effects of pretrial and posttrial administration of cholinergic and anticholinergic drugs on spontaneous alternation. Journal of Comparative and Physiological Psychology, 1969, 69, 69-75.

Stein, L., \& Wise, C. D. Behavioral pharmacology of central stimulants. In W. G. Clark and J. del Giudice (Eds.), Principles of psychopharmacology. New York: Academic Press, 1970.

Sternbach, L. H., Randall, L. O., \& Gustafson, S. R. 1,4-benzodiazepines (chlordiazepoxide and related compounds). In M. Gordon (Ed.), Psychopharmacological agents (Vol. 1). New York: Academic Press, 1964. Pp. 137-224.

Warburton, D. M. The cholinergic control of internal inhibition. In $R$. Boakes and M. S. Halliday (Eds.), Inhibition and learning. London: Academic Press, 1972. Pp. 431-460.

(Received for publication October 9, 1974; revision received November 18,1974 .) 